\title{
POLÍTICAS ITINERANTES DE EDUCAÇÃO E A REESTRUTURAÇÃO DA PROFISSÃO DOCENTE: o papel das cúpulas da OCDE e sua recepção no contexto brasileiro
}

\author{
Dalila Andrade Oliveira \\ Universidade Federal de Minas Gerais (UFMG) \\ Universidade Federal da Paraíba (UFPB)
}

\begin{abstract}
Resumo
O artigo discute a relação entre as políticas itinerantes de educação e a reconfiguração da profissão docente. Com base em pesquisa documental e revisão de literatura, buscou-se compreender como determinadas narrativas sobre a escola e os docentes vão sendo construídas por atores específicos que põem em circulação um conjunto de documentos, relatórios de pesquisa e produção de dados estatísticos que contêm um discurso que se propaga internacionalmente por múltiplas estratégias de difusão. O principal material aqui tratado é a análise dos documentos produzidos pela Organização para a Cooperação e Desenvolvimento Econômico (OCDE), em especial os documentos produzidos para as Cúpulas Internacionais sobre a Profissão Docente. O objetivo é conhecer como o corpus de pesquisa no campo da educação constrói seus objetos e argumentos, em especial no que se refere à reconfiguração da profissão docente da forma como vem sendo definida no discurso que emana dos organismos internacionais. $\mathrm{O}$ artigo está dividido em três partes: a primeira está dedicada à discussão da circulação das políticas de educação em âmbito internacional, seus principais atores e instrumentos; a segunda trata da descrição e análise do material recolhido; e a terceira e última parte aborda a circulação e recepção das recomendações no contexto latino-americano e brasileiro.
\end{abstract}

Palavras-chaves: Profissão Docente; Políticas Itinerantes em Educação; Cúpulas Internacionais sobre a Profissão Docente

\begin{abstract}
The article discusses the relationship between traveling education policies and the reconfiguration of the teaching profession. Based on documentary research and literature review, we sought to understand how specific narratives about the school and the teachers are being built by specific actors who put into circulation a set of documents, research reports and production of statistical data that contain a speech that spreads internationally through multiple dissemination strategies. The main material discussed here is the analysis of the documents produced by the Organization for Economic Cooperation and Development (OECD), in particular the documents produced for the International Summits on the Teaching Profession. The objective is to understand how the research corpus in the field of education constructs its objects and arguments, especially with regard to the reconfiguration of the teaching profession as it has been defined in the discourse that emanates from international organizations. The article is divided into three parts: the first is dedicated to discussing the circulation of education policies at the international level, its main actors and instruments; the second provides a description and analysis of the material collected; and the third and last part addresses the circulation and reception of recommendations in the Latin American and Brazilian context.
\end{abstract}

Keywords: Teaching profession; Traveling policies in Education; International Summits on the Teaching Profession

ISSN 1645-1384 (online) www.curriculosemfronteiras.org

http://dx.doi.org/10.35786/1645-1384.v20.n1.6 
Este artigo tem por objetivo discutir a relação entre as políticas itinerantes de educação e a reconfiguração da profissão docente. Com base em pesquisa documental e revisão de literatura, buscou-se conhecer como o corpus de pesquisa no campo da educação constrói seus objetos e argumentos, em especial no que se refere à reconfiguração da profissão docente da forma como vem sendo definida no discurso que emana dos organismos internacionais. O interesse é conhecer como a literatura acadêmica vem identificando e interpelando discursos hegemônicos em torno da educação e da profissão docente que têm se valido de padrões para identificar, avaliar e determinar o que é a 'boa docência'. Esses discursos buscam definir o papel, as funções e responsabilidades dos professores, tomandoos como uma abstração genérica, e o fazem sob o argumento da busca da eficácia e eficiência nos processos de ensino como forma de atribuir maior qualidade à educação.

Alguns autores tais como Popkewitz e Lindblad (2016) têm discutido como diferentes maneiras de capturar a realidade educacional e transformá-la em números, utilizados como réguas para estabelecer padrões vinculados às formas de ordenar e classificar os alunos, as escolas e os sistemas educacionais em diferentes partes do mundo, foram intensificadas nos últimos tempos. Tal discussão guarda relação com a forma como determinadas políticas circulam no plano internacional e são recebidas em diferentes realidades nacionais que as corporificam como orientações hegemônicas. Este artigo pretende contribuir para a análise de como essas políticas circulam internacionalmente, em especial no contexto latinoamericano e brasileiro, especialmente aquelas dirigidas à profissão docente, identificando atores importantes na produção e difusão dos discursos que se tornam hegemônicos. A intenção é contribuir para o entendimento de como certas narrativas sobre a escola e os professores vão sendo construídas em diferentes espaços e ganham força até se instalarem no senso comum. Essas narrativas têm reorientado os sistemas escolares e reconfigurado a profissão docente na atualidade.

Este artigo é resultado de estudos documentais e teóricos sobre a profissão docente, realizados no âmbito de uma pesquisa em desenvolvimento, intitulada "Políticas públicas para a melhoria do Ensino Médio: socialização científica, tradução e transferência de resultados". A partir desses estudos, buscou-se compreender como determinadas narrativas sobre a escola e os docentes vão sendo construídas por atores específicos que põem em circulação um conjunto de documentos, relatórios de pesquisa e produção de dados estatísticos que contêm um discurso que se propaga internacionalmente por múltiplas estratégias de difusão.

O principal material aqui tratado é a análise dos documentos produzidos pela Organização para a Cooperação e Desenvolvimento Econômico (OCDE) e outros organismos internacionais sobre a profissão docente. Os documentos foram selecionados para a análise por acreditar-se que seus discursos se cruzam com aqueles das políticas formais de Estado e se constituem, em boa parte, fonte de pesquisa da literatura acadêmica. Este estudo está focado mais especificamente nos relatórios das Cúpulas Internacionais sobre a Profissão Docente (International Summit on the Teaching Profession), entre os anos de 2011 e 2019, por considerar que se constituem em importante material de análise sobre as orientações acerca da profissão docente elaboradas em nível internacional. 
A primeira parte do texto está dedicada à discussão da circulação das políticas de educação em âmbito internacional, seus principais atores e instrumentos; a segunda parte trata da descrição e análise do material recolhido nos relatórios das nove Cúpulas Internacionais sobre a Profissão Docente; e a terceira e última parte aborda a circulação e recepção das recomendações dessas Cúpulas no contexto latino-americano e brasileiro.

\section{As políticas itinerantes em Educação: como uma noção de qualidade se instaura no mundo}

As mudanças políticas, econômicas e culturais ocorridas no mundo na passagem do século XX para o atual tiveram repercussões significativas sobre os sistemas educacionais que resultaram de imediato na ampliação das expectativas para a escola e seus profissionais e na reorientação das políticas públicas em educação. Por um lado, essas mudanças trouxeram à tona a crise do modelo de escola republicana baseado no critério de justiça universal: o ideal de igualdade de oportunidades (DUBET, 2004; DEROUET, 2009) e, por outro, colocou em evidência a crise do fazer docente como transmissão de saberes e conhecimento (DUSSEL, 2009). Esses dois aspectos dessa chamada crise sustentaram um movimento de mudança global na área de educação que expressa a circulação de políticas em âmbito mundial.

De acordo com Oliveira e Pal (2018), os estudos sobre transferência, difusão e circulação de políticas são um campo fértil para a inovação no campo da análise de políticas públicas. Os autores argumentam que, no mundo globalizado, a política pública viaja transnacionalmente, permitindo a difusão de políticas que conecta naturalmente a política doméstica à internacional. Essa transferência ocorre por meio de agentes como indivíduos, think tanks, atores não governamentais e organizações internacionais, o que tem sido explorado em profundidade pelos estudos e pesquisas mais recentes sobre o tema.

Para referir a esse movimento de circulação ou mobilidade das políticas em âmbito mundial, recorre-se aqui à expressão 'políticas itinerantes', usada por Lindblad e Popkewitz (2004) para designar conceitos que circulam em reformas educacionais e propostas curriculares, em nível internacional, como resultado dos processos de globalização. Esses autores buscaram compreender como posições argumentativas são apresentadas no paradigma comparativista da educação e quais são as implicações para os discursos da educação. No sentido de procurar verificar quais são os princípios para ordenar, descrever e classificar os problemas e soluções para sistemas educacionais, assim como perceber quais são os atores que estão presentes e quais são os interesses das reformas que se processam sobre a educação, eles têm produzido análises que ajudam a compreender o estado atual das políticas educacionais no mundo e as principais tendências nas orientações das reformas. Buscam compreender as transições em curso como uma referência às mudanças fundamentais que ocorrem nos campos sociais, mas que têm implicações nos padrões de governos concretos da educação e nas maneiras pelas quais conceitos orientadores, amplamente utilizados hoje nos discursos de reforma educacional, tais como inclusão social 
e integração, recebem seus significados. Consideram que essas transições não são homogêneas, mostrando, por meio de resultados de pesquisa, que elas apresentam diferenças em como são realizadas em distintas partes da União Europeia, bem como entre os países no mundo, incluindo desde os industrializados aos de contexto pós-colonial. O conceito de transição é usado pelos autores para fazer uma distinção histórica entre meros eventos na estruturação de sistemas escolares e eventos que adquirem importância teóricohistórica para os padrões de mudança de governança, que incluem a escolaridade e sua relação com a inclusão/exclusão social.

Esse processo de circulação e transferência de políticas educacionais tem relação com o desenvolvimento das pesquisas em educação comparada a partir da segunda metade do século XX (GROUX, 1997; CARNOY, 2019). Os dados estatísticos e os indicadores desenvolvidos pelos organismos internacionais passaram a oferecer informações objetivas que permitem a comparação entre diferentes países. Entretanto, esses dados e indicadores são tomados muitas vezes sem qualquer referência ao contexto social, econômico, histórico e cultural das sociedades que estão sendo comparadas. O argumento para o forte crescimento que os estudos comparados passaram a ter na atualidade está bastante ancorado nas demandas de uma economia globalizada. Justifica-se que por meio desses estudos se espera conhecer os problemas específicos dos sistemas educativos em nível mundial e encontrar soluções globais (DELORS, 1998).

Dessa forma, a educação comparada se apresenta como um campo de investigação que se interessa prioritariamente pelos problemas e propostas estratégicas que permitem reduzir as desigualdades e favorecer a equidade no plano mundial. Nesse sentido, ela possui uma dimensão pragmática, na qual a mobilidade e intercâmbio são fatores importantes (GROUX, 1997). É essa dimensão pragmática que nos interessa interrogar. Em especial porque os estudos produzidos pelos organismos internacionais possuem intencionalidades que vão além da busca da equidade e da redução da desigualdade. Eles se transformam em instrumentos de ordenamento, de classificação, de competição e, portanto, de exclusão.

A OCDE tem desempenhado papel crucial nessa circulação de política, sobretudo pelo caráter pragmático no sentido acima apontado, fornecendo dados e indicadores que permitem comparações e classificações. Por meio do desenvolvimento de estudos e pesquisas, a OCDE tem produzido e acumulado um vasto conhecimento sobre a educação no mundo e por países e regiões específicas (POPKEWITZ e LINDBLAD, 2016; CARVALHO, 2016; GREK, 2016). Os instrumentos produzidos pela OCDE têm se consolidado como importante fonte de informação e, ao mesmo tempo, referência para os países orientarem suas políticas de educação em âmbito nacional.

De acordo com Verger (2019), os organismos internacionais não estão exclusivamente a serviço dos Estados-membros nem simplesmente são a extensão de interesses nacionais particulares. As burocracias desses organismos também são fontes de poder relativamente autônomas que possuem sobre seus membros. Esses organismos possuem, portanto, supremacia como atores no que se refere à circulação de políticas em âmbito internacional.

A circulação das políticas de educação na atualidade está fortemente sustentada pela noção de que a qualidade na educação é uma discussão superada, no sentido de que ela 
deixa de ser um conceito subjetivo e passa a ser definida por um número ou indicador que expressa o que "consensualmente" se espera da educação. Esse movimento é dado em especial pela capacidade das burocracias instauradas nesses organismos internacionais de "tecnificar" a política, mas reflete um processo mais amplo de "cientifização" da vida social e do planejamento estatal para o qual a educação é um objeto que carece de reformas.

A reforma educativa global (REG) é um movimento internacional de mudança na educação que ganha força a partir das últimas décadas do século passado. (VERGER, 2019). A REG parte da internacionalização dos problemas educacionais como estratégia para a regulação das políticas nacionais de educação, em um processo conceituado por Dale (2001) como Agenda Globalmente Estruturada para a Educação (AGEE). De acordo com esse autor, a AGEE é um movimento que busca determinar a quem é ensinado o quê, como, por quem e em que circunstâncias.

Outra sigla também utilizada na literatura contemporânea para designar o movimento internacional atual de mudança na educação é GERM (Global Education Reform Moviment). Sahlberg, em um artigo no The Washington Post, em 29 de junho de 2012, utilizou essa sigla como uma metáfora para expressar suas críticas em relação à forma impressionante como os sistemas educacionais no mundo estavam se tornando semelhantes. Para ele, trata-se de um processo comparável a uma epidemia que se espalha e infecta os sistemas educacionais no mundo como se fosse um vírus. Esse vírus viaja com especialistas, os meios de comunicação e os políticos. Os sistemas educacionais tomam emprestadas políticas de outros países em um processo que ele considera como contaminação. Ainda insistindo nessa metáfora, ele afirma que, como consequência, as escolas adoecem, os professores não se sentem bem e as crianças aprendem menos.

Para Sahlberg (2012), as infecções por GERM têm vários sintomas. O primeiro deles é a promoção de maior concorrência nos sistemas educacionais. Ele destaca que muitos reformadores acreditam que a qualidade da educação melhora quando as escolas competem entre si e que, para competir, elas precisam de mais autonomia e, com essa autonomia, vem a demanda por responsabilidade. Assim, ele atribui à concorrência, semelhante ao mercado, o aumento das inspeções escolares, dos testes padronizados de alunos e da avaliação da eficácia dos professores. Entretanto, adverte que, quando as escolas competem umas com as outras, elas cooperam menos.

Identifica, como segundo sintoma do GERM, a ampliação da escolha da escola. Esse processo posiciona os pais como consumidores, capacitando-os a selecionar escolas para seus filhos a partir de várias opções, promovendo uma concorrência no sistema público similar à dinâmica de mercado. Exemplifica com a informação de que mais de dois terços dos países da OCDE aumentaram as oportunidades de escolha de escolas para as famílias, com a percepção de que os mecanismos de mercado na educação permitiriam acesso igual a todos os tipos de educação de alta qualidade. Um número crescente de escolas charter nos Estados Unidos, academias de escolas secundárias na Inglaterra, escolas gratuitas na Suécia e escolas particulares na Austrália são exemplos de expansão das políticas de escolha de escolas. Mas afirma Sahlberg (2012) que, de acordo com a OCDE, os países que buscam 
essa escolha viram um declínio nos resultados acadêmicos e um aumento na segregação escolar.

O terceiro sintoma do GERM é a responsabilização mais forte das escolas e testes padronizados para os estudantes. Segundo Sahlberg (2012), assim como no mercado, muitos acreditam que responsabilizar professores e escolas pelo aprendizado dos alunos levará a melhores resultados; desse modo, a eficácia do professor, que é medida usando testes padronizados, é um sintoma relacionado ao GERM. Ele ainda ressalta que o teste padronizado tem orientado o processo de ensino tendo como finalidade o exame, reduzido os currículos para priorizar a leitura e a matemática e distanciado o ensino da arte da pedagogia para a instrução mecanicista.

Independente da sigla ou nomenclatura utilizada, são muitas as evidências de que o mundo está conectado por políticas que circulam internacionalmente e que vão atribuindo um sentido comum à qualidade da educação. Os organismos internacionais são atoreschaves nesse processo: mapeando, comparando e evidenciando problemas educacionais, e, ao mesmo tempo, desenvolvendo pacotes de "tecnologias que oferecem uma alternativa politicamente atrativa e eficaz à tradição educacional centrada no Estado e no Bem-Estar público. Elas são postas em confronto e comparadas com as velhas tecnologias do profissionalismo e da burocracia.” (BALL, 2002: p. ??)

Outros atores importantes nesse processo e que merecem destaque pelo grau de influência que exercem sobre agências governamentais e que têm crescido nos últimos tempos são as redes de think tanks. Essas redes são organizações ou instituições que atuam no campo dos grupos de interesse, produzindo e difundindo conhecimento sobre assuntos estratégicos, com vistas a influenciar transformações sociais, políticas, econômicas ou científicas, sobretudo em assuntos sobre os quais pessoas comuns (leigos) não encontram facilmente base para análises de forma objetiva. Os think tanks podem ser independentes ou filiados a partidos políticos, governos ou corporações privadas.

Entretanto, o foco deste artigo está direcionado ao papel dos organismos internacionais, com especial atenção à OCDE, pela centralidade que assume na agenda educacional na atualidade. Apesar de ser um organismo econômico ${ }^{1}$, ela tomou para si essa tarefa, o que reforça uma orientação hegemônica na condução dos sistemas educacionais fundamentada na teoria do capital humano. Como afirma Grek (2016: p.717): “A OCDE transmite todas as mensagens ideológicas 'corretas' para os sistemas educacionais do Século XXI, ou seja, ela conecta a aprendizagem diretamente aos resultados do mercado de trabalho e ao capital humano". A teoria do capital humano exerceu papel fundamental no incremento da educação comparada, em especial no final dos anos 1960 e 1970, ao aliar educação ao crescimento econômico. (CARNOY, 2019) E, todavia, segue predominante.

Os organismos internacionais baseados em forte fundamentação com matriz na teoria do capital humano vêm definindo padrões para identificar, avaliar e determinar o que é a 'qualidade da educação' e a 'boa docência', utilizando de certos dispositivos para influenciar em âmbito internacional a organização dos sistemas educacionais. Esses padrões estão vinculados com formas de ordenar e classificar os estudantes, as escolas e os sistemas educacionais, impondo critérios de eficácia e eficiência em educação para diferentes partes 
do mundo e orientando mudanças na organização dos sistemas educativos nacionais. A OCDE, por meio dos seus estudos, tem reforçado os vínculos entre produtividade, capital humano e políticas educacionais. Nesse sentido, ela recomenda regularmente aos países a reforma de seus sistemas de educação e formação de professores, propondo medidas que mostram que mais capital humano leva a mais produtividade ${ }^{2}$.

Tem sido objeto de nossas investigações como tais questões são recebidas no Brasil, nos diferentes níveis de governo federativo e por diferentes orientações político-partidárias (OLIVEIRA, DUARTE E CLEMENTINO, 2017; OLIVEIRA, 2018; OLIVEIRA, 2019; OLIVEIRA E CLEMENTINO, 2019). Nesse sentido, o propósito aqui é discutir como se desenvolvem esses padrões e processos de transnacionalização e intercâmbio de conhecimentos, ou ainda o que ficou conhecido como "empréstimo de políticas" entre sistemas nacionais e como eles podem mudar na atualidade diante da comparação competitiva global (DALE \& ROBERTSON, 2012).

\section{Como a REG "produz" o docente do século XXI}

A centralidade atribuída aos docentes pela reforma educativa global está fundamentada na constatação de que eles representam o fator com maior impacto nas aprendizagens dos alunos. Nesse sentido, passou a ser uma preocupação constante dos estudos produzidos pela OCDE e outros organismos internacionais identificar, avaliar e definir a 'boa docência'. Entretanto, essa não é uma criação dos organismos internacionais isoladamente, pois encontra suficiente fundamentação em pesquisas acadêmicas com base empírica desenvolvidas em diferentes partes do mundo. As pesquisas sobre escola eficaz passaram a isolar as variáveis componentes do processo escolar que se ocuparam em medir o "efeito escola”; "efeito sala de aula” e "efeito professor”. (BRESSOUX, 2003)

A importância atribuída aos docentes na agenda da reforma educacional global é a justificativa para um dos mais importantes esforços da OCDE que teve início nesta década: as Cúpulas Internacionais sobre Profissão Docente (International Summit on the Teaching Profession). As razões desses esforços podem ser resumidas em um excerto, extraído do relatório da 8. ${ }^{\text {a }}$ Cúpula, revelador da imagem do docente que se espera construir (ou reformar):

Mas esperamos muito mais do que o que colocamos nas descrições de cargo dos professores. Também esperamos que os professores sejam apaixonados, compassivos e atenciosos; tornar o aprendizado central e incentivar o envolvimento e a responsabilidade dos alunos; para responder efetivamente a estudantes de diferentes necessidades, formações e idiomas; promover a tolerância e a coesão social; fornecer feedback e avaliações contínuas dos alunos; e garantir que os estudantes se sintam valorizados e incluídos e que o aprendizado seja colaborativo. E esperamos que os próprios professores colaborem e trabalhem em equipe e com outras escolas e pais, sejam capazes de estabelecer metas comuns e planejar e monitorar a consecução de metas. E há 
mais do que isso. As pessoas de sucesso geralmente tinham um professor que era um mentor e tinham um interesse real em suas vidas e aspirações, que os ajudaram a entender quem são, a descobrir suas paixões e como podem construir pontos fortes, professores que os ensinaram a amar aprender e desenvolver estratégias eficazes de aprendizagem e os ajudaram a descobrir como eles podem fazer a diferença no progresso social. (OCDE, 2018)

Para a organização das Cúpulas, o PISA e a Pesquisa Internacional de Ensino e Aprendizagem (TALIS, na sigla em inglês) - que foi aplicada pela primeira vez em 2008 e se repete a cada cinco anos, com informações sobre a percepção de professores e diretores escolares sobre as condições de trabalho e ambientes de aprendizagem em suas unidades educacionais - são importantes subsídios. A TALIS é a maior pesquisa internacional que recolhe a percepção dos professores e dirigentes escolares sobre suas condições de trabalho e ambientes de aprendizagem com o objetivo de fornecer um barômetro da profissão a cada cinco anos. De acordo com a OCDE, os resultados da edição de 2018 exploram e examinam as várias dimensões do profissionalismo de professores e dirigentes de escolas nos sistemas de ensino. Com base na voz desses sujeitos, "o relatório oferece uma série de orientações políticas para ajudar a fortalecer o conhecimento e as habilidades da força de trabalho de ensino para apoiar seu profissionalismo"3. De acordo com Sorensen e Robertson (2018), a iniciativa para a cúpula foi tomada após a realização da TALIS 2008, sendo que o diretor adjunto de educação da OCDE, Andreas Schleicher, comprometeu-se a redigir o relatório de base da Cúpula (OCDE, 2011), além de desempenhar o papel de criador da agenda.

Essas Cúpulas são realizadas anualmente desde 2011, pela OCDE, mas contam também com a participação da Internacional da Educação (IE), reunindo ministros de educação (ou seus representantes), outras lideranças e especialistas em educação. Nelas são apresentadas e discutidas recomendações políticas sobre as mudanças em educação, apresentam-se experiências exitosas de países com sistemas educacionais de alto desempenho e/ou que têm apresentado rápida melhoria no que se refere aos indicadores, produzindo um efeito de benchmarking de melhores práticas na educação e ensejando a discussão sobre políticas que devem ser adotadas em todo o mundo, tendo em vista um objetivo comum: “excelentes professores e escolas eficazes” (OCDE, 2019).

Nos documentos que circulam a partir da primeira edição, a ênfase é dada na busca de soluções coletivas para problemas apresentados pelos sistemas educativos no mundo. As orientações emanadas dos seus relatórios são difundidas internacionalmente como estratégias para a melhoria da profissão docente e para que os sistemas educativos possam enfrentar os desafios a que estão submetidos.

A primeira Cúpula ocorreu em 2011 e teve como sede a cidade de Nova Iorque. Com o título: "Construindo uma profissão docente de alto desempenho - lições de todo o mundo", a discussão foi desdobrada nos seguintes tópicos centrais: recrutamento e preparação de professores; desenvolvimento profissional, apoio e retenção; avaliação e remuneração de professores; e envolvimento dos professores na reforma da educação. 
Essa Cúpula também reforçou a noção de qualidade educacional como desempenho, tendo o PISA como parâmetro dessa qualidade e o conceito de desenvolvimento profissional docente (DPD), que trata de maior engajamento dos professores na sua formação, sendo protagonistas e responsáveis pelo seu próprio desenvolvimento na profissão.

A Cúpula de 2012 também teve como sede a cidade de Nova Iorque e o tema orientador das discussões foi: "Preparando professores e desenvolvendo lideranças escolares para o século XXI - lições de todo o mundo”, a partir dos seguintes tópicos: desenvolvimento efetivo de lideranças escolares; preparação de professores para corresponderem às habilidades requeridas no século XXI, para que sejam capazes de formar alunos conforme as expectativas do presente século; equilíbrio entre a demanda e a oferta de professores.

A característica comum entre os países participantes dessa Cúpula - Bélgica, Canadá, República da China, Dinamarca, Estônia, Finlândia, Alemanha, Hong Kong, Hungria, Islândia, Indonésia, Japão, República da Coreia, Holanda, Nova Zelândia Cingapura, Eslovênia, Suécia, Suíça, Polônia, Reino Unido e Estados Unidos - foi o bom desempenho no PISA ou uma melhora rápida no programa de avaliação internacional.

Essa Cúpula também reforçou a ideia de uma política itinerante, baseada na evidência local de países centrais que pode ser universalizada e consumida pelos demais países. O relatório sinaliza nessa direção: "O benchmarking internacional tornou-se uma ferramenta importante para a formulação de políticas educacionais” (OCDE, 2012).

A Cúpula de 2013 ocorreu na Holanda e teve como tema: "Professores para o século XXI - usando a avaliação para melhorar o ensino". Como nas edições anteriores, foram selecionados para discussão alguns tópicos centrais: governança e padrões para avaliação de professores; procedimentos para avaliação de professores; competências e capacidades para avaliação de professores; uso dos resultados da avaliação de professores; rumo a uma abordagem coerente de avaliação e accountability.

Os objetivos da Cúpula de 2013 apontam para a ampliação dos mecanismos de avaliação, estendendo o seu alcance aos docentes, reforçando o conceito de desenvolvimento profissional e buscando estabelecer mecanismos de responsabilização:

Por que avaliar professores? Para que os sistemas educacionais das nações alcancem seus objetivos de alto desempenho e alta equidade, eles precisarão de ensino de alta qualidade para todos os estudantes. Assim, para aumentar a qualidade dos professores e a atratividade do ensino como profissão, os países estão implementando políticas que aumentarão a competência e as perspectivas de carreira dos professores. Os sistemas de avaliação de professores são vistos como uma alavanca potencialmente poderosa para melhorar o ensino e oferecer novos papéis para professores excepcionais. Ao mesmo tempo, a escala do investimento público em educação e a necessidade urgente de melhorar os resultados dos estudantes levaram a maiores demandas por responsabilidade. (OCDE, 2013) 
A Cúpula de 2014 foi realizada na cidade de Wellington, Nova Zelândia, e teve como tema: “Equidade, excelência e inclusão na educação - lições políticas de todo o mundo”.

O tema do encontro, ao adotar a frase "políticas de todo mundo", reforça a ideia de uma agenda mundial, de políticas itinerantes, da possibilidade de universalização de práticas locais ainda que em contextos diversos. Nessa cúpula, os tópicos centrais abordados foram: traçar um caminho para a equidade e excelência; desenvolver professores de alta qualidade para escolas com as maiores necessidades; alcançar a equidade em sistemas educacionais cada vez mais descentralizados; criar ambientes de aprendizagem que atendam às necessidades de todas as crianças; construir um sistema educacional equitativo, de excelência e inclusivo.

Essa Cúpula apontou a necessidade de se formar professores em uma perspectiva inclusiva, capazes de transformar os sistemas educacionais em ambientes mais equitativos, sobretudo nas regiões mais vulneráveis.

A Cúpula de 2015 realizou-se no Canadá, na cidade de Banff, tendo como tema: “Implementando Políticas e Práticas de Professores Altamente Eficazes”. O tema foi assim desdobrado: inovar para criar ambientes de aprendizagem no século XXI; construir escolas responsivas para alunos do século XXI; promovendo uma liderança escolar eficaz; fortalecer a confiança de professores em suas próprias habilidades.

A Cúpula desloca a busca pela eficácia do sistema para os professores, cabendo a este impulsioná-los para que se sintam impelidos a formar-se e reformar-se na perspectiva da autoeficácia, estabelecendo metas pessoais para além das preconizadas pelo sistema de ensino, insistindo em uma forte relação entre a autoeficácia dos professores (ou seja, a confiança dos professores em sua capacidade de planejar e realizar atividades para atingir suas metas educacionais) e os resultados dos estudantes.

A Cúpula de 2016, ocorrida na Alemanha, em Berlim, teve como tema "Ensinando excelência através da aprendizagem profissional e reforma política - lições de todo o mundo”. Os tópicos centrais foram: quais conhecimentos, habilidades e qualidades de caráter definem um professor de sucesso?; que políticas podem ajudar os professores a adquirir o conhecimento e as competências necessárias?; o que os governos efetivamente podem fazer para implementar políticas educacionais?; professores profissionais, reformas de sucesso.

O relatório reforça, mais uma vez, a formação inicial e continuada como dimensões do desenvolvimento profissional, devendo ser incorporada pelos professores como ações também pessoais, para que não se corra o risco de descontinuidades por trocas de governo. Enfatiza ainda que a formação deve se dar em serviço e a partir de evidências científicas e práticas exitosas. O conhecimento dos professores “excelentes” e as "provas” de sucesso devem ser incorporados por professores de todo mundo, o que demanda a adesão dos professores às reformas propostas. Sugere ainda o envolvimento de professores destacados e seus sindicatos em diálogos de desenvolvimento de políticas, o que, de acordo com o relatório, demonstra respeito pela profissão, ajuda a gerar confiança entre governo e professores, e torna a política emergente mais provável de ser viável na sala de aula. 
A Cúpula de 2017 teve lugar no Reino Unido, em Edimburgo, e discutiu "Empoderamento e capacitação de professores para a promoção da equidade e resultados para todos”. Os tópicos centrais foram: aprendizagem profissional e desenvolvimento para apoiar o trabalho dos professores; garantir ambiente político e estrutura educacional apropriados em cada país; empenhar-se para a excelência sustentável e a equidade na aprendizagem.

Em março de 2018, em Portugal, foi realizada a 8. ${ }^{\text {a }}$ Cúpula Internacional sobre a Profissão Docente com o tema: "Novos desafios e oportunidades para a profissão docente na educação pública”. Foram evidenciados três eixos de discussão, que se inter-relacionam: escolas no centro de suas comunidades; pedagogias para o futuro; bem-estar, eficácia e eficácia do professor.

As discussões realizadas durante a Cúpula 2018 sinalizaram ações necessárias e urgentes sobre a profissão docente, tais como: a) desenvolver vínculos mais fortes entre escolas e comunidades, especialmente em áreas carentes; b) reduzir a exclusão histórica de crianças de famílias pobres; c) encontrar as formas mais eficazes de aproveitar as novas oportunidades oferecidas pelas tecnologias digitais para inovar pedagogias; d) fornecer espaço e apoio para o desenvolvimento e bem-estar dos professores.

A Cúpula de 2019 foi realizada na Finlândia, com o tema "O futuro do ensino e da aprendizagem”, e pela primeira vez enfatizou a educação e cuidados na primeira infância, pois, segundo o documento, ainda não há consenso entre os países sobre as abordagens pedagógicas destinadas a esse público. O tema foi desdobrado nos seguintes eixos: liderando em conjunto; construir bases sólidas por meio de pedagogias e estratégias inovadoras; em direção a escolas sustentáveis.

No eixo "Liderando em conjunto", o documento discute sobre os desafios multidimensionais de liderança dos sistemas educacionais e quais seriam as ações necessárias para fortalecer a liderança estratégica e a gestão das instituições, promovendo a colaboração. O documento sinaliza que "Sistemas eficazes exigem liderança eficaz em todos os níveis, da política à prática”.

No prefácio do relatório dessa última Cúpula realizada, está sintetizado o papel protagonista que a OCDE pretende exercer na reforma educativa global:

Um dos segredos do sucesso da Cúpula Internacional sobre a Profissão Docente é que ela explora dificuldades e questões controversas com base em evidências sólidas, fornecidas pela OCDE como líder global de dados e análises comparativos.

As Cúpulas Internacionais sobre a Profissão Docente têm se tornado um ponto de referência importante para ações que visam reformar os sistemas educacionais em âmbito global. Elas representam uma mobilização importante de atores políticos, desde os sindicatos, com a participação da mais importante entidade representativa dos trabalhadores em educação, a IE, os governos nacionais que participam ativamente como membros ou convidados e, às vezes, promotores, além de outros organismos internacionais e agências e 
fundações, tais como as think tanks. As orientações políticas difundidas nesses encontros, e por meio dos seus relatórios, embasam-se em dados estatísticos e recolhas de informações que são apresentadas como evidências de práticas e políticas eficazes. Fundamentados por uma concepção econômica de educação, como já ressaltado com uma forte ênfase na teoria do capital humano, os valores defendidos são de uma educação competitiva, que se organize por meio de instrumentos que sejam eficazes para medir os progressos e que premie os mais competentes.

O conceito de discurso hegemônico aqui adotado está inspirado nos estudos de Laclau e Mouffe (1985) que não distinguem o plano discursivo do material e veem os significados como algo que nunca está completamente definido, mas apenas parcialmente fixado por pontos nodais constituídos através de práticas de articulação que consiste na construção de pontos nodais que parcialmente fixam o significado". É nesse sentido que se compreende como os discursos sobre qualidade da educação, "boa docência", "escola eficaz" se difundem pelo mundo como discursos dominantes que alimentam uma lógica competitiva e meritocrática.

Essa lógica meritocrática, sob a qual é muito difícil argumentar contra, sobretudo entre aqueles envolvidos em sociedades altamente desiguais e sem uma segura promessa de futuro, vai se instalando como lógica hegemônica na qual os números expressam "verdades" e classificam sujeitos e instituições. É essa dimensão pragmática que se pretende "neutra" ou "técnica" que precisa ser questionada, pois ainda que em muitos eventos e documentos a inclusão e a equidade sejam pautadas como temas significativos, como se pode observar na Cúpula de 2014, a competição, a meritocracia e a busca de soluções exitosas são a marca fundamental dessas orientações. Em especial, porque os estudos produzidos pelos organismos internacionais possuem intencionalidades que vão além da busca da equidade e da redução da desigualdade. Eles se transformam em instrumentos de ordenamento, de classificação, de competição que são essencialmente econômicos e que, como tais, promovem exclusão. Nunca se falou tanto em reconhecimento à diversidade em um mundo tão unificado por critérios de validação universal.

Como ilustração dessa insistente retórica, é possível identificar somente no texto do prefácio e do sumário executivo da 8. ${ }^{a}$ Cúpula (2018), contendo 10 páginas, a seguinte frequência para as palavras: qualidade (4 vezes); sucesso (10 vezes) e eficácia (9 vezes).

De acordo com o dicionário da língua portuguesa, a qualidade é um conceito subjetivo, definida como o modo de ser, a propriedade de qualificar os mais diversos serviços, objetos, indivíduos, etc. O termo qualidade está relacionado às percepções de cada indivíduo e por isso tem relação com diversos fatores como cultura, produto ou serviço prestado. É também sabido que necessidades e expectativas influenciam diretamente nessa definição. Nesse sentido, a qualidade diz respeito à percepção dos sujeitos, seus valores culturais e morais e suas formas de pertencimento social.

De acordo com o mesmo dicionário, a eficácia é um substantivo feminino que designa a qualidade daquilo que alcança os resultados planejados; característica do que produz os 
efeitos esperados, do que é eficaz. Capacidade de desenvolver tarefas ou objetivos de modo competente; está intimamente relacionada com produtividade.

E por fim, sucesso significa ter êxito em alguma coisa, algum projeto. Esse termo também é carregado de intencionalidade, ser exitoso em um projeto é alcançar os objetivos pretendidos, ter e saber a priori aonde se deve chegar.

Esses são termos que são difundidos nesses discursos sobre a educação e tomados, muitas vezes, de forma acrítica, sem reflexão. Eles expressam valores e intencionalidades e fazem parte de um repertório que compõe um novo modo de regulação da educação.

De acordo com Normand (2018: p.21), a introdução de critérios de eficácia na reestruturação e na desregulação dos sistemas educativos erige novas culturas profissionalizantes e de gestão dos atores em educação, orientada para políticas de accountability que começam a perceber os docentes como parte do problema. Para ele, "enquanto os professores são convidados a se engajar em um desenvolvimento profissional contínuo, as medidas de auditoria recolocam a abordagem tradicional de inspeção e a metodologia de autoavaliação se instala nos estabelecimentos de ensino." Tudo isso em nome de ajudar os professores a realizar seus potenciais e melhorar a qualidade da educação.

\section{As políticas itinerantes no contexto latino-americano e brasileiro}

Os processos de reforma do Estado iniciados nos anos 1990 na região latino-americana tiveram a introdução da Nova Gestão Pública (NGP) como importante instrumento na relação entre os atores do Estado e da sociedade civil (Oliveira, 2015). Os princípios da NGP foram determinando novas formas de regulação da educação baseadas em políticas de prestação de contas para as quais a avaliação passou a ter um papel essencial. Essa regulação tem definido novos processos de escolarização, centrados na aprendizagem, posto em discussão as formas tradicionais de financiamento público da educação e interferido na construção de novas identidades docentes e nas suas relações profissionais.

Os Estados reformados pela NGP buscam soluções para os problemas públicos no setor privado e, assim, procuram constantemente refazer o contrato com a sociedade, por meio de parcerias que se apresentam como uma relação cooperativa entre o mundo dos negócios, as instâncias governamentais locais e as comunidades. (POPKEWITZ, 2008). São contratos supostamente monitorados por meio de prestação de contas que os seus agentes devem apresentar tanto ao Estado quanto à sociedade. Eles se intensificam na política educacional brasileira nos últimos anos, tanto no que se refere à contratação de metas internamente às redes de ensino, entre escolas e órgão intermediários (secretarias de educação, gerências regionais de educação, etc.), como por meio das parcerias público-privadas no fornecimento de material escolar, programas de formação docente em exercício ou pela transferência da gestão da escola para Organizações Sociais ${ }^{4}$.

Nesse sentido, a transparência passa a ser em tese um valor importante no contexto da NGP e ela deve ser obtida por meio da prestação de contas. Esses contratos pressupõem, 
portanto, um envolvimento responsável dos agentes, já que implicam em estabelecimento de metas e prestação de contas do que foi acordado. As avaliações surgem nesse cenário como um importante instrumento de prestação de contas, utilizado tanto para estabelecer os parâmetros (metas) que se busca atingir com os contratos quanto para medir os progressos obtidos. Esse processo de contratualização na educação pública acaba por instituir um sistema de responsabilização.

Por sistema de responsabilização é possível designar o conjunto de políticas e práticas que o Estado usa para medir e responsabilizar escolas por elevar o desempenho dos alunos e para estimular e apoiar a melhoria quando necessário. De acordo com Anderson (2005), no campo da educação, existem três tipos principais de sistema de responsabilização: (a) cumprimento de regulamentos, (b) adesão a normas profissionais e (c) resultados impulsionados.

Tais sistemas têm crescido em larga escala no mundo, sobretudo, a partir da segunda metade do século XX. Isso se deve em grande medida ao fato de que os sistemas comparativos de avaliação em larga escala foram sendo desenvolvidos em âmbito internacional e passaram a ser cada vez mais recorrentes para definir o padrão de qualidade educacional dos diferentes países que se submetem aos testes. Nesse sentido, os exames internacionais têm funcionado cada vez mais como instrumentos de circulação e transferências de políticas educacionais em âmbito mundial, com destaque para o PISA (BRADFORD, 2008; RIZVI \& LINGARD, 2012).

As constantes críticas aos sistemas educacionais pelo seu baixo desempenho, verificado sobretudo nas provas do PISA, realizadas nos países da América do Sul, em especial o Brasil, com resultados bem abaixo dos parâmetros de rendimento dos estudantes pertencentes aos países-membros da OCDE, têm contribuído para aumentar a desconfiança da sociedade em relação às escolas e seus docentes.

Os países latino-americanos estão nas últimas posições no ranking mundial do PISA, juntos com os países do norte da África. Dias, Mariano e Cunha (2017) realizaram um estudo a partir dos resultados do PISA 2015 em que buscaram analisar a realidade socioeconômica da educação pública básica dos sete países da América Latina que participaram do PISA naquela edição. O objetivo do estudo foi relacionar esse conhecimento sobre a realidade dos sete países com os resultados do PISA, mostrando a sua evolução, considerando o período de 2006 a 2015, e identificar possíveis fatores que podem explicar o desempenho observado nessa região. Estudos dessa natureza têm crescido respondendo à ampliação da abrangência do teste na região. Outra evidência da crescente relevância do PISA na região é o peso que passou a ter internamente aos países na determinação legal dos seus parâmetros de qualidade. No Brasil, a Lei 13005/2015, que dispõe sobre o Plano Nacional de Educação para um período de 10 anos, estabeleceu em sua meta 7 , dedicada à avaliação, na sua estratégia 7.11, que a proficiência do PISA é a meta a ser alcançada no período de vigência do Plano (BRASIL, 2014).

Outro considerável exemplo da ampliação do escopo do teste foi a criação do PISA para o Desenvolvimento (PISA-D), em 2013, construído especificamente para ser adotado em países de 'renda baixa e média' (ADDEY, 2016). A autora discute a importância da 
realização do teste considerando os contextos desses países, que poderão produzir dados politicamente mais relevantes para os seus sistemas educacionais. A iniciativa contou com participação ativa de países da América do Sul, como Equador e Paraguai.

O contexto político atual que atravessa boa parte dos países latino-americanos, marcado por uma forte regressão no que se refere aos direitos sociais, pelo conservadorismo moral e pela austeridade em matéria financeira combinada à acentuada concentração de renda, tende a exacerbar as consequências desses processos de regulação educacional, produzindo ainda mais desigualdade e promovendo maior injustiça social.

Os professores são apontados como peças-chaves para a qualidade da educação nos discursos que circulam internacionalmente e, na região latino-americana, como podemos constatar em documentos produzidos pela OCDE, o Banco Mundial, a Organização dos Estados Ibero-americanos (OEI), o Banco Interamericano de Desenvolvimento (BID), a Organização das Nações Unidas para a Educação, a Ciência e a Cultura (Unesco) e a Comissão Econômica para a América Latina e o Caribe (Cepal). Esse discurso, que enfoca a responsabilidade dos professores por melhorar o desempenho dos estudantes nas avaliações externas em contexto de grande desigualdade social, tem contribuído para uma perda de confiança nos professores como profissionais por parte da sociedade e uma depreciação de sua carreira e profissionalismo (Oliveira, 2018). Além disso, os professores sentem como sua posição profissional é constantemente desrespeitada em uma cultura frequente de "auditoria" (BERLINER, 2013; ANDERSON, 2017; GUROVA, \& PIATTOEVA, 2018).

Como analisado por Pettersson e Mosltad (2016), nos relatórios do PISA, "bons" professores e ensino "efetivo" são apresentados como estratégias que permitem que os estudantes socialmente desfavorecidos alcancem aqueles mais favorecidos, levando à equalização. Para esses autores, o PISA constrói uma visão específica de como os professores são compreendidos e cujas ações são ricas em conteúdo, ou seja, os professores são modelados ou construídos a partir dessas histórias. Dessa forma, o discurso construído pelos organismos internacionais para as reformas educacionais desenvolve estratégias manipuladoras, de fabricação ou modelagem das identidades de professores.

Esses discursos chegam até os espaços de formulação e implementação de política nas distintas realidades nacionais como lógicas dominantes e vão promovendo mudanças na gestão da educação e das carreiras e condições de trabalho dos docentes. (OLIVEIRA, 2018; VILLANI \& OLIVEIRA, 2018; CUENCA, 2015). Em um contexto federativo, como o caso brasileiro, combinando formas descentralizadas de financiamento e mais flexíveis de gestão, esse novo modelo de regulação tem incorporado uma grande diversidade de instituições privadas na oferta da educação pública, sejam as Organizações Sociais assumindo a gestão da escola pública (como Escolas Charters), seja por meio dos livros didáticos e material pedagógico, ou ainda na formação dos profissionais em serviço. Esse novo modo de regulação, mais flexível e menos regulamentado, está baseado nos critérios da economia privada em contraposição à lógica do bem-comum que deveria ser garantido pelo poder público. 
No que concerne ao contexto latino-americano, essas orientações emanadas das Cúpulas têm sido difundidas na região por meio de eventos e documentos que replicam suas discussões e recomendações, tais como: I Reunión Regional de Ministros de Educación de América Latina y Caribe, ocorrida em Buenos Aires, Argentina, entre os dias 24 e 25 de janeiro de 2017 e II Reunión Regional de Ministros de Educación de América Latina y el Caribe, ocorrida entre os dias 25 e 26 de julho de 2018, em Cochabamba, Bolívia.

Essas recomendações chegam à região latino-americana em um contexto já bastante sensibilizado pela necessidade de mudança para alcançar o desenvolvimento almejado, herança histórica de onde se desenvolveu a teoria da dependência. De acordo com Baker (2012), a aliança entre o realismo, a racionalidade e o colonialismo moldaram visões desenvolvimentistas do mundo sob as quais se sustentam essas políticas. Essa é uma constante no contexto regional que sofre há mais de meio século a influência direta dos organismos internacionais na agenda da educação ${ }^{5}$. A forte presença que tem esses organismos na América Latina pode ser constatada nos muitos eventos internacionais que promovem e nos numerosos estudos produzidos para governos nacionais, normalmente insistindo na especificidade de uma agenda regional, tendo maior capilaridade naqueles países que não possuem suas próprias estruturas de produção de dados. Dessa maneira, buscam fornecer informações que sejam supostamente relevantes para estudantes e profissionais da educação, mas, sobretudo, que sejam úteis para os formuladores e implementadores de políticas públicas nos governos da região. Entretanto, é sabido também que a OCDE exerce relação direta com os países latino-americanos prescindindo-se da intermediação dos organismos regionais.

Os estudos produzidos pelos organismos internacionais para a região confluem com essas recomendações. A Unesco, em relatório sobre a formação docente, em 2012, conclui que o entorno profissional docente apresenta problemas, tais como dificuldades para reter os 'bons professores', e que os novos docentes são vistos como deficitários em relação às expectativas com respeito a seu desempenho. Afirma ainda que são escassos os estímulos para que a profissão docente seja a primeira opção de carreira entre os jovens ingressantes na educação superior, além de constatar que as condições de trabalho são inadequadas e apresentam sérios problemas na estrutura de remunerações e incentivos. Constatações muito próximas, e até mais incisivas, são encontradas em documento produzido pelo Banco Mundial para a região latino-americana, intitulado 'Professores excelentes', em que se observa textualmente: A evidência disponível sugere que a América Latina não está atraindo as pessoas de alto calibre de que precisa para construir sistemas educacionais de classe mundial. (BRUNS; LUQUE, 2014: p. 10)

As recomendações emanadas das Cúpulas ressaltam ainda a importância de se investir em mudanças na formação de professores como um dos elementos centrais das reformas educacionais, com o objetivo de um necessário aprimoramento da formação docente e a melhoria dos indicadores de desempenho dos estudantes. De acordo com seus organizadores, a participação amplia os diálogos, permitindo que os participantes saiam de seu contexto e estabeleçam padrões de pensamento, aprendam com as evidências 
comprovadas de práticas eficazes em outros lugares e que podem, segundo a OCDE, serem universalizadas a partir de seu trânsito por diferentes contextos.

Dessa forma, podemos considerar que a OCDE desenvolve uma governação por números, difundindo lógicas hegemônicas que vinculam diretamente qualidade da educação a valor econômico, reduzindo a indicadores numéricos realidades sociais e culturais variadas e complexas, exercendo forte influência sobre um grupo crescente de países, extrapolando o conjunto de seus membros.

Por meio dos discursos proferidos desde lugares autorizados, por exemplo, a voz dos especialistas que trabalham sobre os testes e seus relatórios, estabelece-se um sistema de verdade fundamentada na objetividade do dado numérico oferecido. Assim, as políticas internacionais viajam, por meio de uma abordagem de política baseada em evidências. Como afirma Verger, (2019) "Tal prática seletiva significa que a pesquisa viaja diretamente da ideologia a recomendações de políticas, e usa a ciência e a evidência principalmente como um quadro de legitimação".

De acordo com Popkewitz \& Lindblad (2016), os números circulam e são conectados por um sistema de razão que lhes atribui inteligibilidade para promover as reformas educacionais. Esses processos estão a serviço de fabricar teorias e programas que influenciam como os professores ensinam, como as famílias e as crianças/jovens pensam sobre si mesmos, mas também, e antes de tudo, como o professor se vê. De acordo com os mesmos autores, a estatística funciona como uma forma particular de fundamentação para o governo das sociedades atuais, como um elemento de controle da vida social moderna, influenciando a criação de regras que utiliza a noção de fabricação. Noção que tem um duplo sentido: de ficção e de construção de tipos de pessoas que a educação pode administrar, para domar a mudança e a vida moderna 'incerta' por meio do fornecimento de ferramentas administrativas que estabilizam e harmonizam as relações sociais.

Portanto, para os autores, as comparações estatísticas dos desempenhos dos estudantes enfatizam os componentes que dizem respeito à seleção e desenvolvimento profissional de professores, bem como as categorias psicológicas da criança e da família que não consegue êxito nas avaliações. As fabricações são versões de uma organização (ou pessoa) que não existe, elas são produzidas propositadamente para serem explicáveis.

Assim vai se produzindo um discurso do que é uma escola eficaz, um diretor eficiente e bons professores. Discursos que vão estabelecendo modelos, tipos ideais ou imaginados, que elegem alguns exemplos para serem seguidos (nunca se viu tanta premiação em educação!). Entretanto, esse é um processo que leva à exclusão: a fabricação exclui outras coisas que não se ajustem ao que se pretende que seja representado ou transmitido. (BALL, 2002: 15)

O que se observa, com base em pesquisas no contexto brasileiro e na literatura sobre o tema em diferentes realidades nacionais, é que as políticas de prestação de contas têm promovido uma verdadeira artificialidade da escola, no sentido de que já não são os coletivos escolares que definem seus projetos pedagógicos, que estabelecem suas prioridades de acordo com seus contextos. Ao contrário, são as metas que são contratadas com as secretarias de educação ou órgãos intermediários que definem a organização do 
cotidiano escolar. As escolas trabalham no sentido de responder às metas (OLIVEIRA, DUARTE E CLEMENTINO, 2017). Nesse contexto, o diretor exerce papel crucial, buscando envolver os docentes dentro de um projeto que vem de fora, do que é bonito para ser visto, no que pode ser auditado. As escolas, para se adequarem às exigências de desempenho, tornam seus projetos educativos esvaziados.

Esse processo coloca em risco a autenticidade da escola que, como observa Ball (2002), corre o risco de ser inteiramente substituída pela plasticidade. Para ele, essas tecnologias de gestão não deixam espaço para um ser ético autônomo ou coletivo. Isso leva à profunda mudança na natureza da relação dos trabalhadores e o seu trabalho compromissos de serviço já não têm valor ou significado e o julgamento, ou avaliação profissional, está subordinado às exigências da performatividade. Assim, os professores e a formação docente se converteram na preocupação principal dos esforços da reforma global e que se replica no interior de muitos países. O enfoque tem sido como manejar melhor as atividades dos professores para produzir um ensino mais efetivo, no sentido da melhoria do rendimento dos estudantes. Para isso, promovem o que Ball (2002) identificou como um mecanismo dirigido a "Reformar professores e para mudar o que significa ser professor!"

Dessa forma, a REG desenvolve outros modos de regulação dos professores que apelam para o seu compromisso individual. Esses modelos de regulação transitam do controle burocrático, baseado em normas e regras estáveis, exaustivamente descritas, abrangentes e aplicadas de forma impessoal, cumpridas por meio de um poder hierárquico, para modos mais flexíveis que implicam os sujeitos pelo compromisso pessoal, o envolvimento e a incorporação dos objetivos institucionais como próprios. Esse processo se assenta na lógica meritocrática, no esforço individual que merece recompensa.

De acordo com Ball (2002), o Estado proporciona um novo modo de regulação menos visível, mais liberal e autorregulado, em que há exigência de autonomia e a obrigação de iniciativa. Nesse modo de regulação, os professores são encorajados a refletir sobre si próprios como indivíduos que fazem cálculos sobre si, aumentam sua produtividade. Novas formas de disciplina são colocadas pela competição, eficiência e produtividade e novos sistemas éticos são introduzidos, baseados no autointeresse institucional, pragmatismo e valor performativo. $\mathrm{O}$ ato de ensinar e a subjetividade do professor estão ambos profundamente alterados dentro de uma nova visão de gestão que persegue resultados, que tem seu desempenho constantemente medido, em suma, baseada na competição.

Para Ball (2002), esse processo tem efeitos diretos sobre os docentes, tanto no sentido do aumento da individualização, incluindo a destruição de solidariedades baseadas numa identidade profissional comum, e em relação à filiação em sindicatos, contra a construção de novas formas de filiação e comunidade. Ainda de acordo com o mesmo autor, os docentes, cada vez mais submetidos aos "riscos de serem valorizados apenas pela sua produtividade", veem-se envolvidos em um "fluxo de exigências em mudança, expectativas $e$ indicadores que os tornam continuamente responsáveis e constantemente observados". (BALL, 2002: 10). Por isso, ele considera que são muitos os custos pessoais e psicológicos para esses trabalhadores: 
Um tipo diferente de esquizofrenia é vivido por professores individualmente, sendo o compromisso e a entrega, o julgamento e a autenticidade dentro da prática sacrificados pela impressão e o desempenho. Aqui há potencial ruptura entre os julgamentos dos próprios professores acerca do que é uma 'boa prática' e as necessidades dos estudantes e os rigores do desempenho. (BALL, 2002: 12)

A abstração do docente prático-reflexivo, tido como o docente do século XXI, é adicionada a programas, teorias e narrativas sobre o perito e o professor profissional que lida com crianças. O professor torna-se um solucionador de problemas e, ao mesmo tempo, um sujeito empreendedor que deve zelar pelo seu próprio desempenho e desenvolvimento profissional, mesmo que não tenha qualquer segurança e apoio para tal.

\section{Comentários finais}

No contexto latino-americano, observa-se como, cada vez mais, os testes padronizados, em especial o PISA, têm atuado como uma tecnologia de poder que vem sendo adotada como referência de qualidade da educação pelos governos, vem colonizando os professores e apresentando ideias colonialistas aos estudantes em formas legítimas, impondo uma agenda corporativa em âmbito global (VIRURU, 2006). Na realidade, o PISA tem atuado como uma forma particular de tecnologia inquestionável, que é sustentada tanto por governos de matriz mais à direita quanto por governos progressistas como uma avaliação “objetiva” do desempenho de escolas e estudantes, que revela a verdade que deve ser considerada.

Isso ocorre por meio do que pode ser considerado como um processo de politização dos resultados do PISA. Como afirmam Salokangas e Kauko (2015, p: 1355), é raro que os pesquisadores questionem a excelência da qualidade da análise quantitativa do PISA, contudo, a comparabilidade de seus resultados, sua limitada abrangência e as repercussões políticas provocadas por ele têm sido alvo de críticas. Os mesmos autores insistem que os usos políticos que se faz dos resultados do PISA desconsideram o contexto social do aprendizado e adulteram comparações complexas, transformando-as num jogo simplista de números. Eles chamam a atenção para dois fatos que são normalmente negligenciados nos processos de empréstimo de políticas: 1) a dificuldade de operar mudanças políticas em conformidade com uma política educacional estabelecida; 2) o fato de que, em geral, os resultados baseiam-se em evidências questionáveis servindo muito mais ao objetivo de legitimar reformas do que propriamente de importar uma política específica.

A intenção deste artigo foi justamente contribuir na compreensão de como esses discursos se difundem entre governos, organismos internacionais e outras agências, envolvendo decisores políticos, consultores, pesquisadores acadêmicos e até os professores e estudantes, revelando um movimento das políticas de educação que circulam pelo mundo e que transitam do global ao local. 
Nessas políticas que têm por objetivo reformar a educação, os professores são peçachave e a formação docente se converteu na preocupação principal dos esforços da reforma. O enfoque tem sido como preparar os professores para responderem aos objetivos da reforma, como manejar melhor as atividades dos professores para produzirem um ensino mais efetivo, no sentido da melhoria do rendimento dos estudantes no PISA e nos testes nacionais.

Estamos diante de um processo pelo qual a mudança política, as reformas e as reestruturações têm sido facilitadas pela "reconfiguração discursiva dos parâmetros da possibilidade e da aceitabilidade política. Políticas são construídas dentro e ao redor de discursos específicos que são eles mesmos conjuntos de práticas que sistematicamente produzem os objetos dos quais falam...” (MAGUIRE E BALL, 2007: p. 97-98)

\section{Notas}

1. Criada em 1948 como Organisation for European Economic Co-operation European (OEEC); em 1961 foi reformada, passando a se chamar Organisation for Economic Co-operation and Development (OECD, na sigla em inglês).

2. Ver: https://www.oecd.org/economy/human-capital/ Consultado em 06/03/2020.

3. https://www.oecd-ilibrary.org/education/talis-2018-results-volume-i_1d0bc92a-en (tradução livre da autora)

4. Conferir estudo realizado no âmbito desta pesquisa sobre a política educacional atual nos nove estados da região nordeste do país. OLIVEIRA, D.A., DUARTE, A.M.C., RODRIGUES, C. (2019)

5. Já em 1958, com o Seminário Interamericano sobre Planejamento Integral da Educação, realizado em Washington, sob os auspícios da Organização dos Estados Americanos (OEA) e da UNESCO, foi acordada a iniciativa de organizar a Conferência Interamericana sobre Educación e Desarrollo Económico y Social, que ocorreu em Santiago do Chile, em março de 1962, com a participação da CEPAL, da Organização Internacional do Trabalho (OIT), da Organização das Nações Unidas para a Alimentação e Agricultura (FAO) e a Organização Mundial de Saúde (OMS).

\section{Referências}

ADDEY, C. O PISA para o desenvolvimento e o sacrifício de dados com relevância política. Educ. Soc. [online]. 2016, vol.37, n.136, pp.685-706.

ANDERSON, G. Privatizando subjetividades: como a nova gestão pública (NGP) está criando o "novo" profissional da educação. RBPAE, v. 33, n. 3, p. 593-626, set/dez. 2017

ANDERSON, J.A. Accountability in Education. International Academy of Education International Institute for Educational Planning. Paris-France: UNESCO, 2005.

BAKER, B. Isso é tudo? As limitações do global/local, PISA e o dilema da pesquisa sobre o currículo transnacional. Currículo sem Fronteiras, v. 12. N. 3, p. 190-216, set/dez. 2012.

BALL, S. Reformar escolas/reformar professores e os terrores da performatividade. Revista Portuguesa, 2002, 15(2). Universidade do Minho. P. 03-23

BERLINER, D. Effects of Inequality and Poverty vs. Teachers and Schooling on America's Youth. Teachers College Record. Volume 115 Number 12, 2013

BRADFORD, N. The OECD's local turn. In R. Mahon \& S. McBride (Eds.) The OECD and transnational governance (134-151). Vancouver: UBC Press, 2008. 
BRASIL. Presidência da República. Lei $n^{o}$ 13.005, de 25 de junho de 2014. Aprova o Plano Nacional de Educação - PNE e dá outras providências. 2014. Brasília, DF, 2014.

BRESSOUX, P. As pesquisas sobre o efeito-escola e o efeito-professor. Educação em Revista, Belo Horizonte, FAE/UFMG, n. 38, p. 17-88, 2003.

BRUNS, B.; LUQUE, J. Professores Excelentes - Como melhorar a aprendizagem dos estudantes na América Latina e no Caribe. Washington, D.C.: Banco Mundial, 2014.

CARNOY, M. Transforming comparative education. Fifty years of theory building at Stanford. Stanford University Press; $1^{\mathrm{a}}$. Ed., 2019

CARVALHO, L. M. Intensificação e Sofisticação dos Processos da Regulação Transnacional em Educação: O Caso do Programa Internacional De Avaliação de Estudantes. Educ. Soc. [online]. 2016, vol.37, n.136, pp.669-683.

CUENCA, R. Las carreras docentes em América Latina. La acción meritocrática para el desarollo profesional. OREALC/UNESCO: Santiago (Chile), 2015.

DALE, R. Globalização e educação: demonstrando a existência de uma cultura educacional mundial comum ou localizando uma agenda globalmente estruturada para a educação. Educação, Sociedade e Culturas, Porto, Portugal, n. 16, p. 133-169, 2001.

DALE, R. \& ROBERTSON, S. Além dos ismos metodológicos na educação comparada em uma era de globalização. COHEN, R., KAZAMIAS, A.M. \& ULTERHALTER, E. Educação comparada: panorama internacional e perspectivas. Brasília: UNESCO, CAPES, 2012. Vol. 2

DELORS, J. et al. Educação: um tesouro a descobrir: relatório para a UNESCO da Comissão Internacional sobre Educação para o Século XXI. São Paulo: Cortez; Brasília, DF: UNESCO, 1 998.

DEROUET, J. L. Les recompositions parallèles des formes de l'Etat et des formes de justice. In: DEROEUT, J. L.; DEROUET, M. C. (Ed) Repenser la justice dans le domaine de l'education et de la formation. Lyon, INRP, 2009, p. 3-23.

DIAS, B. F.B., MARIANO, S. R. H.; CUNHA, R. M. Educação básica na América Latina: uma análise dos últimos dez anos a partir dos dados do programa internacional de avaliação de estudantes (PISA). Revista Pensamento Contemporâneo em Administração, vol. 11, núm. 4, jul-set, 2017, pp. 1-26 Universidade Federal Fluminense, Rio de Janeiro, Brasil

DUBET, F. O que é uma escola justa? Cadernos de Pesquisa. São Paulo: 2004, v. 34, n. 123, p. 539-555.

DUSSEL, I. A transmissão cultural assediada: metamorfoses da cultura comum na escola. Cadernos de Pesquisa, São Paulo, v. 39, n. 137, p. 351-365, 2009.

GREK, S. Atores do Conhecimento e a Construção de Novos Cenários de Governança: O Caso da DireçãoGeral de Educação e Cultura da Comissão Europeia. Educ. Soc. [online]. 2016, vol.37, n.136, pp.707-726.

GROUX, D. L'éducation comparée: approches actuelles et perspectives de développement. Revue Française de Pédagogie, Rouen: 1997. vol. 21, n¹21, 111-139

GUROVA, G. \& PIATTOEVA, N. A postsocialist perspective on audit culture: changing practices and subjectivities of school teachers in a Russian region. In NORMAND, R., LIU, M., CARVALHO, L. M., OLIVEIRA, D. A., \& LEVASSEUR, L. (Eds.). Education Policies and the Restructuring of the Educational Profession: Global and Comparative Perspectives (pp.1-12). Springer, 2018.

LACLAU, E., MOUFFE, C. Hegemony and Socialist Strategy: Towards a Radical Democratic Politics, Londres: Verso, 1985.

LINDBLAD, S. \& POPKEWITZ, T. (Editors). Educational Restructuring: International Perspectives on Traveling Policies. Information Age Publishing, 2004. 
MAGUIRE, M. \& BALL, S. Discursos da reforma educacional no Reino Unido e estados Unidos e o trabalho dos professores. Práxis Educativa. Ponta Grossa, PR. V. 2, n. 2, p. 97- 104., Jul-dez, 2007.

NORMAND, R. A modernização "eficaz" da profissão de professor confrontada às novas políticas de accountability. Revista da FAEEBA. Educação e Contemporaneidade, v. 27, n. 53, 2018.

OLIVEIRA, D.A. A reestruturação da profissão docente no contexto da nova gestão pública na América Latina. Revista da FAEEBA. Educação e Contemporaneidade. v. 27, n. 53, 2018.

OLIVEIRA, D.A. Nova gestão pública e governos democrático-populares: contradições entre a busca da eficiência e a ampliação do direito à educação. Educ. Soc., Campinas, v. 36, nº. 132, p. 625-646, jul.-set., 2015.

OLIVEIRA, D.A., DUARTE, A. W. E CLEMENTINO, A. M. A Nova Gestão Pública no contexto escolar e os dilemas dos(as) diretores(as). RBPAE - v. 33, n. 3, p. 707 - 726, set./dez. 2017

OLIVEIRA, D.A. e CLEMENTINO, A.M. As políticas de responsabilização na educação básica nos estados do nordeste. In: OLIVEIRA, D.A., DUARTE, A.M.C., RODRIGUES, C.M.L. A política educacional em contexto de desigualdade: uma análise das redes públicas de ensino da região nordeste. Campinas: Mercado das Letras, 2019.

OLIVEIRA, O. P. de e PAL, L. A. Novas fronteiras e direções na pesquisa sobre transferência, difusão e circulação de políticas públicas: agentes, espaços, resistência e traduções. Rev. Adm. Pública, vol. 52, nº 2, Rio de Janeiro, mar/abr., 2018

PETTERSSON, D. \& MOLSTAD, C. E.. Professores do PISA: a esperança e a realização da educação. Educ. Soc. [online]. 2016, vol.37, n.136, pp.629-645.

POPKEWITZ, T \& LINDBLAD, S. A fundamentação estatística, o governo da educação e a inclusão e exclusão sociais. Educ. Soc. [online]. 2016, vol.37, n.136, pp.707-726.

POPKEWITZ, T. S. Uma perspectiva comparativa das parcerias, do contrato social e dos sistemas racionais emergentes. In: TARDIF, M.; LESSARD, C. (Org.) O ofício de professor: história, perspectivas e desafios internacionais. Petrópolis: Vozes, 2008.

RIZVI, F., LINGARD, B. A OCDE e as mudanças globais nas políticas de educação. COHEN, R., KAZAMIAS, A.M. \& ULTERHALTER, E. Educação comparada: panorama internacional $e$ perspectivas. Brasília: UNESCO, CAPES, 2012.Vol. 1

SAHLBERG, P. How GERM is infecting schools around the world? The Washington Post, 29 de junho, 2012.

SALOKANGAS, M. e KAUKO, J. Tomar de empréstimo o sucesso finlandês no PISA? Algumas reflexões críticas, da perspectiva de quem faz este empréstimo. Educação e Pesquisa, São Paulo, v. 41, n. especial, p. 1353-1365, dez., 2015

SORENSEN, T.B., \& ROBERTSON, S.L. The OECD program TALIS and Framing, Measuring and Selling Quality Teacher ${ }^{\mathrm{TM}}$ in M. Akiba \& G.K. Le Tendre (eds.). Routledge International Handbook of Teacher Quality and Policy. Routledge, 2018

VERGER, A. A política educacional global: conceitos e marcos teóricos chave. Revista Práxis Educativa, Ponta Grossa, v. 14, n. 1, jan/abr. 2019.

VILLANI, M.; OLIVEIRA, D. A. Avaliação Nacional e Internacional no Brasil: os vínculos entre o PISA e o IDEB. Educação \& Realidade, v. 43, n. 4, pp. 1343-1362, Out/Dez, 2018.

VIRURU, R. Postcolonial Technologies of Power: Standardized Testing and Representing Diverse Young Children. International Journal of Educational Policy, Research, \& Practice: Reconceptualizing Childhood Studies Volume 7, 2006. 


\section{Documentos consultados}

ASIA SOCIETY (2011). Improving teacher quality around the world. The 2011 International Summit on the Teaching Profession. New York: Asia Society. Disponível em AsiaSociety.org/teachingsummit. Acesso em: 02/03/2019.

(2012). Teaching and leadership for the twenty-first century. The 2012 International Summit on the Teaching Profession. New York: Asia Society. Relatório disponível em AsiaSociety.org/teachingsummit. Acesso em: 02/03/2019.

(2013). Teacher Quality. The 2013 International Summit on the Teaching Profession. New York: Asia Society. Disponível em: AsiaSociety.org/teachingsummit. Acesso em: 02/03/2019.

(2014). Excellence, Equity, and Inclusiveness. High Quality Teaching for All. The 2014 International Summit on the Teaching Profession. Wellington, New Zealand: Asia Society. Disponível em: AsiaSociety.org/teachingsummit. Acesso em: 02/03/2019.

(2015). Implementing Highly Effective Teacher Policy and Practice. The 2015 International Summit on the Teaching Profession. Banff, Canadá: Asia Society. Disponível em: AsiaSociety.org/teachingsummit. Acesso em: 02/03/2019.

(2016). Teachers' professional learning and growth: creating the conditions to achieve quality teaching for excellent learning outcomes. The 2016 International Summit on the TeachingProfession. Berlim, Alemanha: Asia Society. Disponível em: AsiaSociety.org/teachingsummit. Acesso em: 02/03/2019.

(2017). Empowering and Enabling Teachers to Deliver Improved Equity and Outcomes for All. The 2017 International Summit on the Teaching Profession. Edimburg, Escócia: Asia Society. Disponível em: AsiaSociety.org/teachingsummit. Acesso em: 02/03/2019.

SCHLEICHER, A. (2018), Valuing our Teachers and Raising their Status: How Communities Can Help, International Summit on the Teaching Profession, OECD Publishing, Paris. http://dx.doi.org/10.1787/9789264292697-en

SCHLEICHER, A. (2019), Helping our Youngest to Learn and Grow: Policies for Early Learning, International Summit on the Teaching Profession, OECD Publishing, Paris, https://doi.org/10.1787/9789264313873-en.

\section{Correspondência}

Dalila Andrade Oliveira: É professora titular de Políticas Públicas em Educação do Programa de PósGraduação em Educação da Universidade Federal de Minas Gerais. Professora Visitante do Programa de Pós-Graduação em Educação da Universidade Federal da Paraíba. Pesquisadora PQ-1A/CNPq. Coordenadora do Grupo de Estudos Sobre Políticas Educacionais e Trabalho Docente http://www.gestrado.net.br

E-mail: dalila@ufmg.br

Orcid: https://orcid.org/0000-0003-4516-6883

Texto publicado em Currículo sem Fronteiras com autorização da autora 